Dementia

and Geriatric

Cognitive Disorders
Dement Geriatr Cogn Disord 2017;44:45-54

DOI: $10.1159 / 000477718$

Accepted: May 22, 2017

Published online: July 5, 2017
(C) 2017 S. Karger AG, Basel

www.karger.com/dem

\title{
Visual Ratings of Medial Temporal Lobe Atrophy Correlate with CSF Tau Indices in Clinical Variants of Early-Onset Alzheimer Disease
}

\author{
Elias Granadillo ${ }^{a, c}$ Pongsatorn Paholpak ${ }^{a, c, d} \quad$ Mario F. Mendez ${ }^{a-c}$ \\ Edmond Teng ${ }^{\text {a, } c}$ \\ Departments of a Neurology and ${ }^{b}$ Psychiatry and Behavioral Sciences, David Geffen \\ School of Medicine at UCLA, and 'Veterans Affairs Greater Los Angeles Healthcare System, \\ Los Angeles, CA, USA; d Department of Psychiatry, Faculty of Medicine, Khon Kaen \\ University, Khon Kaen, Thailand
}

\section{Keywords}

Biomarkers · Cerebrospinal fluid · Early-onset Alzheimer disease · Magnetic resonance imaging $\cdot$ Tau

\begin{abstract}
Background/Aims: Prior studies of late-onset Alzheimer disease (AD) have reported that cerebrospinal fluid (CSF) tau levels correlate with hippocampal/medial temporal lobe atrophy. These findings suggest that CSF tau indices in AD may reflect tau-related neurodegeneration in the medial temporal lobe. However, it remains uncertain whether elevated CSF tau levels in the clinically heterogeneous subtypes of early-onset AD (EOAD; amnestic, posterior cortical atrophy $[\mathrm{PCA}]$, and logopenic progressive aphasia [LPA]) are attributable to similar underlying mechanisms. Methods: We identified 41 EOAD patients (18 amnestic, 14 with LPA, and 9 with PCA) with CSF and brain MRI data. Semiquantitative ratings were used to assess medial temporal lobe atrophy and PCA, which were compared to CSF biomarker indices. Results: Lower CSF tau levels were seen in PCA relative to amnestic EOAD and LPA, but similar ratings for medial temporal lobe atrophy and PCA were seen across the groups. After adjustments for demographics and cognitive performance, both total $(p=0.004)$ and hyperphosphorylated $(p=0.026)$ tau levels correlated with medial temporal lobe atrophy across this EOAD cohort. Conclusions: These results replicate prior findings in late-onset $A D$ and support the hypothesis that CSF tau levels primarily reflect tau-related neurodegenerative changes in the hippocampus/medial temporal lobe across the clinical subtypes of EOAD.

(c) 2017 S. Karger AG, Basel
\end{abstract}

Edmond Teng, MD, PhD

Easton Center for Alzheimer's Disease Research at UCLA

710 Westwood Plaza

Los Angeles, CA 90095 (USA)

E-Mail eteng@ mednet.ucla.edu 


\section{Introduction}

Sporadic early-onset Alzheimer disease (EOAD; age $\leq 65$ years) has been categorized into three primary subtypes based on the predominant domain of initial cognitive symptomatology: (1) amnestic (memory); (2) logopenic progressive aphasia (LPA; language); and (3) posterior cortical atrophy (PCA; visuospatial) [1]. While these EOAD subtypes are primarily defined by their clinical features, prior work has indicated that they can also be distinguished by their regional patterns of underlying Alzheimer disease (AD) neuropathology [2-4], cortical atrophy on MRI [5-11], and hypometabolism on FDG-PET [7, 11-15]. Despite these differences, all three subtypes have shown similar profiles for $\beta$-amyloid (A $\beta$ ) biomarker indices, including indistinguishable patterns of increased $A \beta$ deposition on PET imaging [12, $13,15,16]$ and consistently low levels of $A \beta_{42}$ in the cerebrospinal fluid (CSF) [11, 16-27].

What remains less certain is whether CSF tau indices differ between these clinical EOAD subtypes. While several studies have suggested similar elevations in CSF total tau (t-tau) and phosphorylated tau (p-tau) across subtypes [11, 16-18, 20-22, 26, 27], others have raised the possibility that CSF $\mathrm{t}$-tau and/or p-tau levels may be significantly lower in PCA relative to amnestic or LPA variants of EOAD $[19,24,25]$. These divergent findings have generated multiple hypotheses regarding the mechanistic implications of elevations in CSF tau indices in EOAD [24].

Amongst individuals at different stages of late-onset AD, many [28-34] (though not all $[35,36])$ previous studies have demonstrated significant correlations between CSF tau indices and hippocampal/medial temporal lobe atrophy. In classification analyses of AD patients, these CSF and imaging biomarker abnormalities are often (though not always) seen in conjunction $[37,38]$. On the basis of these findings, it has been postulated that elevations in CSF tau indices in AD reflect regional neurodegeneration [31] attributable to the deposition of neurofibrillary tangles (NFTs) [32], particularly in the hippocampus [30]. Such conclusions are consistent with other work suggesting that CSF biomarkers for AD may most closely reflect neuropathology in periventricular regions [39].

Investigations into the relationship between CSF tau indices and regional atrophy in EOAD subtypes may further clarify this relationship, given the more diverse patterns of NFT deposition across this patient population [2-4]. However, previous work investigating CSF biomarker indices and cerebral atrophy in EOAD subtypes using voxel-based morphometry (VBM) somewhat surprisingly failed to show significant correlations between CSF tau measures and regional cerebral volumetric measurements [27]. In the work presented below, we used another approach for measuring regional brain atrophy on MRI, semiquantitative visual ratings $[40,41]$, to determine whether prior reports of correlations between medial temporal lobe atrophy and CSF tau indices at different stages of late-onset AD are similarly applicable across EOAD variants.

\section{Subjects and Methods}

\section{Participants}

We performed a retrospective chart review of patients seen in the UCLA Neurobehavior Clinic, which focuses on the diagnosis and management of early-onset dementias, between 2002 and 2015. We identified 41 patients with an initial symptom onset before the age of 65 years who fulfilled the diagnostic criteria for probable amnestic EOAD $(n=18)$ [42], LPA $(n=14)$ [43], or PCA $(n=9)[2,44]$ and had both CSF biomarker and brain MRI data available for review. The CSF indices for 24 of these patients had been included in a previous analysis [24]. All patients underwent assessments that included clinical history taking, the MiniMental State Examination (MMSE) [45], and neurological and neurobehavioral examinations. CSF biomarker levels and brain MRI images were either obtained at UCLA or available from prior medical evaluations. This retrospective review of patient records was approved by the UCLA Institutional Review Board. 
Granadillo et al.: Visual Ratings of Medial Temporal Lobe Atrophy Correlate with CSF

Tau Indices in Clinical Variants of Early-Onset Alzheimer Disease

CSF Analyses

The CSF samples were analyzed by Athena Diagnostics (Worcester, MA, USA) for A $\beta_{42}$, t-tau, and p-tau using commercially available ELISA kits (INNOTEST $\beta$-Amyloid(1-42), INNOTEST hTau Ag, and INNOTEST Phospho-Tau(181P); Innogenetics, Ghent, Belgium). p-tau measurements were not available for 2 patients in the LPA group and 1 patient in the amnestic group.

Visual Rating Assessments of MRI

Two trained and independent raters blinded to the patients' clinical data (E.G. and P.P.) performed semiquantitative visual ratings of both medial temporal lobe atrophy [40] and PCA [41]. Such ratings can be performed and compared across images obtained from multiple different scanners.

Visual assessments of medial temporal lobe atrophy were performed on coronal images [40]. Noncontrast T1-weighted sequences were preferentially used for these analyses, but for a subset of patients, only $\mathrm{T} 2$-weighted and/or post-contrast T1-weighted sequences were available. The medial temporal lobe atrophy scores ranged from 0 (no atrophy) to 4 (severe atrophy). Visual assessments of PCA were based on the examination of axial sequences in conjunction with coronal and/or sagittal sequences [41]. The PCA scores ranged from 0 (no atrophy) to 3 (severe atrophy). When scores for specific patients from an individual rater differed by orientation, the highest score was used. For each rater, the right and left medial temporal lobes and the right and left posterior cortical regions were rated separately prior to being averaged together to derive a composite score for each region. Visual atrophy ratings for the medial temporal lobe for 1 patient in the amnestic EOAD group and for the posterior cortex for 1 patient in the PCA group were not performed due to missing MRI sequences.

\section{Data Analyses}

Statistical analyses were performed using SPSS 23 for Mac (IBM, Armonk, NY, USA). Demographic data were compared between the diagnostic groups using one-way ANOVA for continuous variables and KruskalWallis tests for categorical variables. CSF biomarker data and MRI visual atrophy ratings were compared between the diagnostic groups using Kruskal-Wallis tests. Post hoc analyses were Bonferroni corrected for multiple comparisons where appropriate. The degree of agreement between the independent visual MRI raters was assessed using intraclass correlation coefficients (ICCs). ICC values $<0.4$ denote poor agreement, values between 0.4 and 0.59 denote fair agreement, values between 0.6 and 0.74 denote good agreement, and values $>0.74$ denote excellent agreement [46]. Associations between MRI atrophy ratings and CSF biomarker data were assessed with Spearman's rank correlation coefficients for unadjusted analyses and multiple linear regression for adjusted analyses.

\section{Results}

The demographic data for the patients with amnestic EOAD, LPA, and PCA with valid CSF and MRI data available for analysis are shown in Table 1. The three EOAD groups were similar in gender distribution, age at symptom onset, age at lumbar puncture (LP), symptom duration at LP, MMSE score at LP, and interval between MRI and LP ( $p$ values $<0.05$ ).

The box plots for the CSF indices in the three EOAD groups are shown in Figure 1. Similar $\mathrm{A} \beta_{42}$ levels were seen across all three groups (Fig. $1 \mathrm{a} ; \chi^{2}(2,41)=0.06, p=0.97$ ). However, significant group differences were seen in t-tau (Fig. $1 \mathrm{~b} ; \chi^{2}(2,41)=9.12, p=0.010$ ) and $p$-tau (Fig. 1c; $\chi^{2}(2,38)=7.76, p=0.021$ ) levels. Bonferroni-corrected post hoc Mann-Whitney U comparisons (critical $p<0.017$ ) revealed significantly higher t-tau $(Z(27)=-2.98, p=0.003$ ) and p-tau $(Z(26)=-2.61, p=0.009)$ levels in amnestic EOAD relative to PCA. Marginally higher t-tau $(Z(23)=-2.39, p=0.017)$ and $p$-tau $(Z(21)=-2.27, p=0.023)$ levels were seen in LPA relative to PCA.

The ICC analyses of the consistency of the visual atrophy scores between the two blinded raters indicated excellent agreement for the left (ICC $=0.82$ ) and right (ICC $=0.79$ ) medial temporal lobes and for the left (ICC $=0.84$ ) and right (ICC $=0.86$ ) posterior cortical regions, comparable to that reported by other groups [47]. Wilcoxon signed-rank tests indicated 
Granadillo et al.: Visual Ratings of Medial Temporal Lobe Atrophy Correlate with CSF Tau Indices in Clinical Variants of Early-Onset Alzheimer Disease

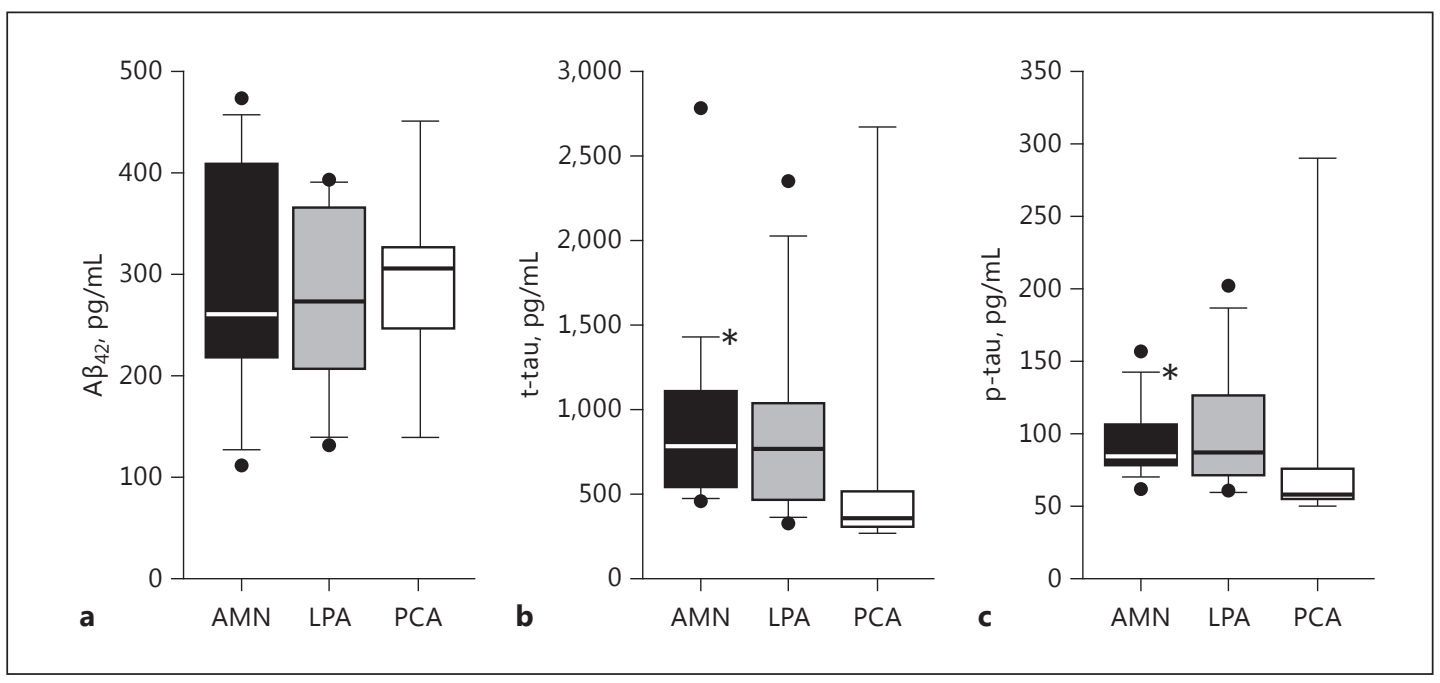

Fig. 1. Box plots for cerebrospinal fluid levels of $A \beta_{42}$ (a), total tau (t-tau) (b), and phosphorylated tau (p-tau) (c) in the amnestic early-onset Alzheimer disease (AMN), logopenic progressive aphasia (LPA), and posterior cortical atrophy (PCA) groups. * $p<0.017$ versus PCA group.

Table 1. Demographic data

\begin{tabular}{lcccc}
\hline & Amnestic & LPA & PCA & $F(2,38) / \mathrm{c}^{2}(2,41)$ \\
\hline Subjects, $n$ & 18 & 14 & 9 & \\
Male, \% & 61 & 43 & 33 & 2.15 \\
Age at symptom onset, years & $53.2(4.9)$ & $55.8(4.6)$ & $54.0(5.3)$ & 1.09 \\
Age at LP, years & $56.3(4.1)$ & $59.0(5.3)$ & $57.2(5.6)$ & 1.20 \\
Symptom duration at LP, years & $3.1(1.8)$ & $3.2(2.4)$ & $3.2(1.8)$ & 0.01 \\
MMSE score at LP & $22.1(6.3)$ & $17.2(8.1)$ & $20.3(4.4)$ & $2.09^{\mathrm{a}}$ \\
LP-to-MRI interval, months & $8.9(12.9)$ & $14.9(19.4)$ & $5.8(5.2)$ & 1.23 \\
\hline
\end{tabular}

Values in parentheses denote standard deviations. LPA, logopenic progressive aphasia; PCA, posterior cortical atrophy; $\mathrm{LP}$, lumbar puncture. ${ }^{\mathrm{a}} \mathrm{df}=2,37$ due to missing data for 1 patient in the amnestic group.

similar atrophy ratings for the left and right medial temporal lobes and left and right posterior cortical regions for each rater (all $p$ values $>0.05$ ). Therefore, for each rater and region, the atrophy scores were averaged across the hemispheres to generate regional composite scores, which were then averaged across the raters for subsequent analyses. The visual atrophy ratings for the medial temporal and posterior cortical regions in the three EOAD groups are shown in Figure 2. Similar regional atrophy scores were seen across the groups in both the medial temporal lobe (Fig. $2 \mathrm{a} ; \chi^{2}(2,40)=0.19, p=0.91$ ) and the posterior cortex (Fig. $2 \mathrm{~b}$; $\left.\chi^{2}(2,40)=2.02, p=0.36\right)$.

We subsequently sought to determine whether regional visual atrophy scores correlated with CSF biomarker indices. Unadjusted analyses indicated that medial temporal lobe atrophy ratings were significantly correlated with CSF t-tau levels (Fig. 3a; $r_{\mathrm{s}}(40)=0.38, p=0.015$ ) and marginally correlated with CSF p-tau levels (Fig. 3b; $r_{\mathrm{s}}(37)=0.28, p=0.098$ ) but were not correlated with CSF A $\beta_{42}$ levels $\left(r_{\mathrm{s}}(40)=0.03, p=0.85\right)$. PCA ratings did not correlate with 
Dementia

and Geriatric

Cognitive Disorders
Dement Geriatr Cogn Disord 2017;44:45-54

DOI: $10.1159 / 000477718$

Fig. 2. Box plots for visual atrophy ratings of the medial temporal (a) and posterior cortical (b) regions in the amnestic earlyonset Alzheimer disease (AMN), logopenic progressive aphasia (LPA), and posterior cortical atrophy (PCA) groups.

Granadillo et al.: Visual Ratings of Medial Temporal Lobe Atrophy Correlate with CSF Tau Indices in Clinical Variants of Early-Onset Alzheimer Disease
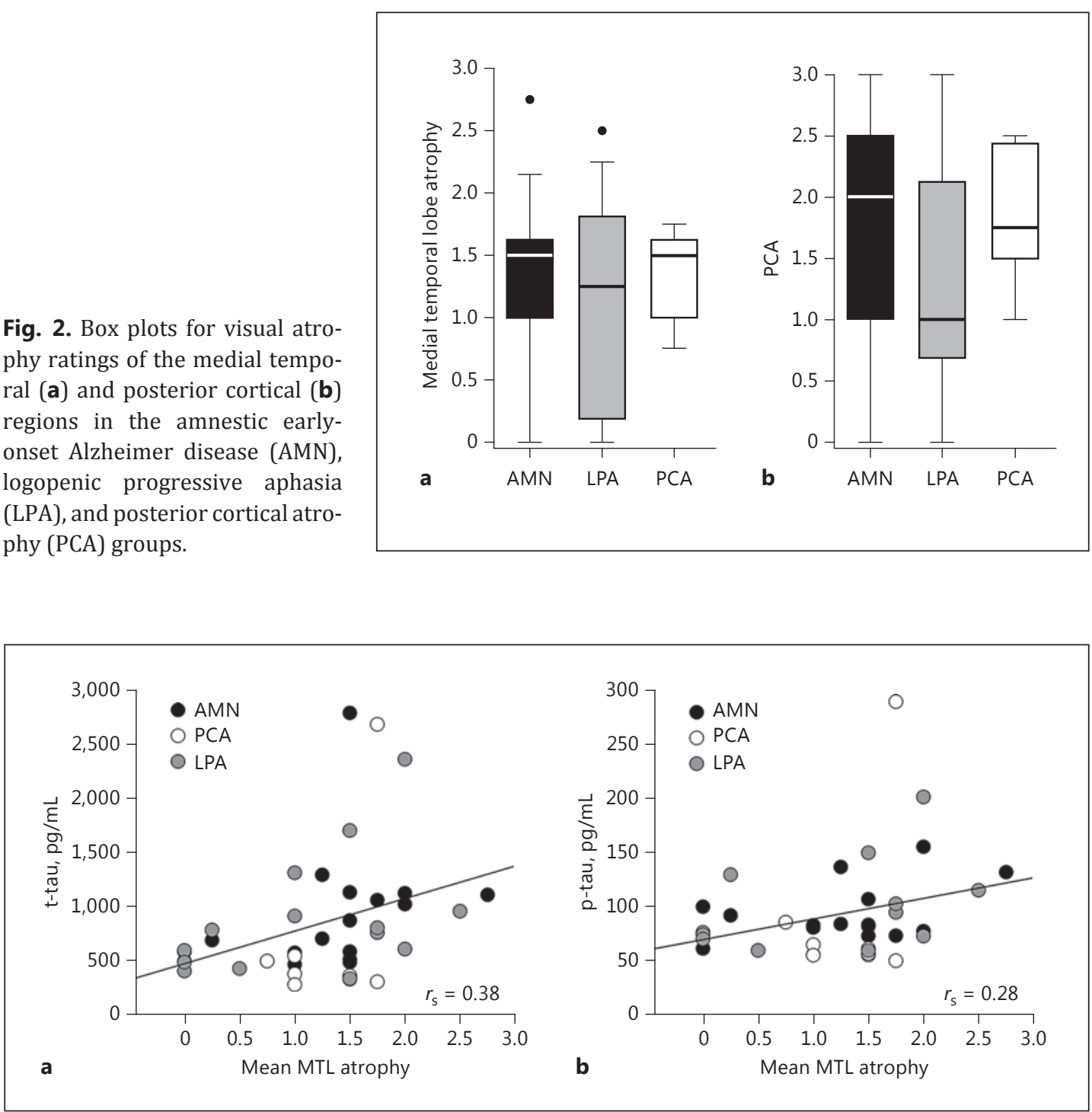

Fig. 3. Unadjusted correlations between cerebrospinal fluid total tau (t-tau) (a) and phosphorylated tau (ptau) (b) levels and visual ratings of medial temporal lobe (MTL) atrophy across the amnestic early-onset Alzheimer disease (AMN), logopenic progressive aphasia (LPA), and posterior cortical atrophy (PCA) groups.

CSF t-tau $\left(r_{\mathrm{s}}(40)=0.13, p=0.42\right)$, p-tau $\left(r_{\mathrm{s}}(37)=-0.13, p=0.46\right)$, or $\mathrm{A} \beta_{42}\left(r_{\mathrm{s}}(40)=0.10, p=\right.$ $0.55)$ levels.

Although there are conflicting reports in the literature regarding the association between demographic factors and CSF AD biomarkers, a subset of studies have suggested that age [48, 49], sex [50], and MMSE scores [49, 51] may modulate CSF tau indices. Therefore, we performed additional multiple regression analyses of CSF t-tau and $\mathrm{p}$-tau versus visual atrophy ratings to adjust for these potentially confounding variables (Table 2). The adjusted analyses indicated that ratings of medial temporal lobe atrophy were significantly associated with both t-tau $(p=0.004)$ and $p$-tau $(p=0.026)$ across the entire EOAD cohort. However, the adjusted analyses failed to show any significant associations between ratings of PCA and CSF tau indices (data not shown). 
Granadillo et al.: Visual Ratings of Medial Temporal Lobe Atrophy Correlate with CSF Tau Indices in Clinical Variants of Early-Onset Alzheimer Disease

Table 2. Multiple regression analysis of CSF t-tau and p-tau levels across the amnestic EOAD, LPA, and PCA groups

\begin{tabular}{|c|c|c|c|c|c|c|}
\hline & \multicolumn{3}{|l|}{ t-tau } & \multicolumn{3}{|l|}{ p-tau } \\
\hline & $\beta$ & $t$ & $p$ & $\beta$ & $t$ & $p$ \\
\hline Sex & 0.32 & 2.44 & 0.020 & 0.20 & 1.32 & 0.198 \\
\hline Age & -0.44 & -3.37 & 0.002 & -0.35 & -2.23 & 0.033 \\
\hline MMSE score & -0.06 & -0.47 & 0.640 & 0.07 & 0.45 & 0.658 \\
\hline Medial temporal lobe atrophy & 0.41 & $\begin{array}{c}3.09 \\
r=0.64\end{array}$ & 0.004 & 0.37 & $\begin{array}{c}2.33 \\
r=0.50\end{array}$ & 0.026 \\
\hline
\end{tabular}

The reference condition for sex is male. CSF, cerebrospinal fluid; $t$-tau, total tau; $p$-tau, phosphorylated tau; EOAD, early-onset Alzheimer disease; LPA, logopenic progressive aphasia; PCA, posterior cortical atrophy.

\section{Discussion}

Our analyses of CSF AD biomarkers and semiquantitative MRI regional atrophy ratings across the clinical subtypes of EOAD demonstrate significant associations between CSF tau indices and atrophy in the medial temporal lobes but not in the posterior cortical regions. These findings are consistent with prior work in cohorts with participants in the prodromal and dementia stages of late-onset $\mathrm{AD}$ indicating that volumetric measurements of hippocampal atrophy correlate with CSF t-tau and/or p-tau levels [28-34], and they provide additional support for the hypothesis that elevated CSF tau indices in AD primarily reflect NFTdriven neurodegenerative changes in the hippocampus and medial temporal lobes [30-32].

Similar to our prior report (which included 24 of the patients studied here) [24], CSF t-tau and p-tau levels were lower in PCA than in amnestic EOAD or LPA. The literature regarding CSF tau indices in PCA remains inconsistent; a few studies have reported lower tau levels in PCA relative to other EOAD subtypes [19, 24, 25], but others have not [11, 16-18, 20-22, 27]. While the diagnostic criteria for PCA are well established $[2,44]$, subtle differences in their operationalization across research groups may have resulted in the inclusion of different subsets of PCA patients across studies.

We used regional visual atrophy ratings as a proxy for severity of neurodegeneration and NFT deposition. Somewhat unexpectedly, all three EOAD subgroups had similar overall atrophy ratings for the medial temporal and posterior cortical regions. Previous studies comparing AD subtypes have reported greater medial temporal and hippocampal atrophy in typical or amnestic AD $[5-7,9,10]$, greater parietal/occipital atrophy in PCA $[5,6,10]$, and greater left temporal/parietal atrophy in LPA $[7,8]$. The absence of group differences in our visual atrophy rating indices may be related to the smaller sample sizes for our analyses or the potentially poorer precision of visual ratings relative to volumetric analyses. Additionally, since the CSF studies were conducted for clinical purposes, our cohort may have been enriched by patients with more atypical presentations [24]. Alternatively, our findings may reflect the partially overlapping networks of neurodegeneration that are seen across EOAD subtypes, particularly with disease progression [52].

The associations between medial temporal lobe atrophy and CSF tau indices seen in our EOAD patients mirror prior work in late-onset AD [29-34], despite the different overall patterns of atrophy between these $\mathrm{AD}$ subtypes [53]. One interpretation of these results is that CSF t-tau and p-tau levels, much like CSF A $\beta_{42}$ levels [39], correlate most strongly with periventricular AD pathology. Recent work examining tau PET imaging with AV-1451 in late- 
onset AD has shown a significantly elevated uptake in the medial temporal lobes [54]. Likewise, a significantly higher medial temporal lobe AV-1451 uptake is seen in amnestic EOAD, LPA, and PCA patients relative to controls [15], suggesting that elevations in CSF tau levels in EOAD may also be largely due to medial temporal lobe tau deposition. A definitive exploration of this hypothesis in EOAD awaits further studies of correlations between CSF tau indices and regional tau PET tracer uptake, particularly since CSF tau indices appear to correlate with tau PET signals in individuals with late-onset cognitive impairment across a number of regions, including the medial temporal lobes [54].

The results presented here differ from those of Ossenkoppele et al. [27], who demonstrated similar CSF t-tau and p-tau levels across amnestic EOAD, LPA, and PCA groups and failed to show significant correlations between these indices and cerebral volumetric measurements using VBM. These discrepant results could have arisen from our use of semiquantitative ratings of regional visual atrophy (which were not adjusted for the degree of global cerebral atrophy) rather than volumetric measurements. However, the Scheltens medial temporal lobe rating scale [40] correlates closely with VBM [47], tensor-based morphometry [55], and other volumetric approaches to measuring hippocampal size [56, 57]. Nevertheless, it is perhaps notable that a prior study examining visual ratings of medial temporal lobe atrophy in mild cognitive impairment failed to find a correlation with CSF t-tau levels [36]. Alternatively, there may be inherent differences in EOAD cohort composition, as the participants in the study by Ossenkoppele et al. [27] were significantly older and had higher CSF $A \beta_{42}$ levels than those included in our analyses.

A number of factors may limit the interpretation of our findings. The data were retrospectively gathered via chart review, and only a small proportion of the EOAD patients seen in the UCLA Neurobehavior Clinic had both CSF and MRI data available for review. This subgroup may not be entirely representative of our patient population. All patients received a clinical diagnosis of EOAD from a single rater (M.F.M.), but we did not have neuropathological confirmation of an underlying AD pathology. Prior postmortem studies have suggested that some PCA $[2,58,59]$ and LPA [3, 4] patients may have a non-AD neuropathology. However, all of our EOAD patients had CSF $A \beta_{42}$ levels $<500 \mathrm{pg} / \mathrm{mL}$, which has previously been used as a threshold suggestive of $\mathrm{AD}[18,20]$. The associations between medial temporal lobe atrophy ratings and CSF tau indices were relatively modest in magnitude, suggesting that other factors, including NFT deposition in other periventricular regions, are also likely to contribute to CSF tau levels in AD. MR images were obtained with multiple scanners, and the specific sequences available for review differed between the patients. However, the visual atrophy rating scales used in this study are likely to produce results that are robust across scanners and sequences $[40,41]$. The CSF samples and MR images were not collected on the same day, which may have attenuated the association between these AD biomarkers. Nevertheless, the intervals between these measures amongst our participants are comparable to those in prior studies that demonstrated significant correlations between CSF tau indices and hippocampal atrophy [30] or regional tau PET tracer uptake [54] in late-onset AD.

Our results showing significant correlations between medial temporal atrophy and CSF tau indices across EOAD subtypes are concordant with the hypothesis that CSF tau levels in EOAD may be predominantly driven by hippocampal and/or medial temporal lobe NFT deposition, as has previously been postulated for late-onset AD [30-32]. However, these findings do not exclude other potential explanations for the diversity of CSF tau levels across EOAD subtypes [24], which include the possibility of greater etiologic heterogeneity in some cohorts [19] and/or different rates of disease progression between EOAD variants. Future studies that directly examine the relationship between CSF tau indices and regional tau PET tracer uptake in EOAD may be needed to confirm our conclusions. 
Granadillo et al.: Visual Ratings of Medial Temporal Lobe Atrophy Correlate with CSF

Tau Indices in Clinical Variants of Early-Onset Alzheimer Disease

\section{Acknowledgments}

Our research was supported by the Sidell-Kagan Foundation and the National Institute on Aging (R01 AG050967).

\section{Disclosure Statement}

There are no conflicts of interest or other disclosures to report.

\section{References}

1 Mendez MF: Early-onset Alzheimer's disease: nonamnestic subtypes and type 2 AD. Arch Med Res 2012;43: 677-685.

2 Tang-Wai DF, Graff-Radford NR, Boeve BF, Dickson DW, Parisi JE, Crook R, Caselli RJ, Knopman DS, Petersen RC: Clinical, genetic, and neuropathologic characteristics of posterior cortical atrophy. Neurology 2004;63: 1168-1174.

3 Mesulam M, Wicklund A, Johnson N, Rogalski E, Léger GC, Rademaker A, Weintraub S, Bigio EH: Alzheimer and frontotemporal pathology in subsets of primary progressive aphasia. Ann Neurol 2008;63:709-719.

4 Mesulam MM, Weintraub S, Rogalski EJ, Wieneke C, Geula C, Bigio EH: Asymmetry and heterogeneity of Alzheimer's and frontotemporal pathology in primary progressive aphasia. Brain 2014;137:1176-1192.

5 Whitwell JL, Jack CR Jr, Kantarci K, Weigand SD, Boeve BF, Knopman DS, Drubach DA, Tang-Wai DF, Petersen RC, Josephs KA: Imaging correlates of posterior cortical atrophy. Neurobiol Aging 2007;28:1051-1061.

6 Lehmann M, Crutch SJ, Ridgway GR, Ridha BH, Barnes J, Warrington EK, Rossor MN, Fox NC: Cortical thickness and voxel-based morphometry in posterior cortical atrophy and typical Alzheimer's disease. Neurobiol Aging 2011;32:1466-1476.

7 Madhavan A, Whitwell JL, Weigand SD, Duffy JR, Strand EA, Machulda MM, Tosakulwong N, Senjem ML, Gunter JL, Lowe VJ, Petersen RC, Jack CR Jr, Josephs KA: FDG PET and MRI in logopenic primary progressive aphasia versus dementia of the Alzheimer's type. PLoS One 2013;8:e62471.

8 Josephs KA, Dickson DW, Murray ME, Senjem ML, Parisi JE, Petersen RC, Jack CR Jr, Whitwell JL: Quantitative neurofibrillary tangle density and brain volumetric MRI analyses in Alzheimer's disease presenting as logopenic progressive aphasia. Brain Lang 2013;127:127-134.

9 Manning EN, Macdonald KE, Leung KK, Young J, Pepple T, Lehmann M, Zuluaga MA, Cardoso MJ, Schott JM, Ourselin S, Crutch S, Fox NC, Barnes J: Differential hippocampal shapes in posterior cortical atrophy patients: a comparison with control and typical AD subjects. Hum Brain Mapp 2015;36:5123-5136.

10 Wang XD, Lu H, Shi Z, Cai L, Liu S, Liu S, Han T, Wang Y, Zhou Y, Wang X, Gao S, Ji Y: A pilot study on clinical and neuroimaging characteristics of Chinese posterior cortical atrophy: comparison with typical Alzheimer's disease. PLoS One 2015;10:e0134956.

11 Peng G, Wang J, Feng Z, Liu P, Zhang Y, He F, Chen Z, Zhao K, Luo B: Clinical and neuroimaging differences between posterior cortical atrophy and typical amnestic Alzheimer's disease patients at an early disease stage. Sci Rep 2016;6:29372.

12 Rosenbloom MH, Alkalay A, Agarwal N, Baker SL, O’Neil JP, Janabi M, Yen IV, Growdon M, Jang J, Madison C, Mormino EC, Rosen HJ, Gorno-Tempini ML, Weiner MW, Miller BL, Jagust WJ, Rabinovici GD: Distinct clinical and metabolic deficits in PCA and AD are not related to amyloid distribution. Neurology 2011;76:1789-1796.

13 Lehmann M, Ghosh PM, Madison C, Laforce R Jr, Corbetta-Rastelli C, Weiner MW, Greicius MD, Seeley WW, Gorno-Tempini ML, Rosen HJ, Miller BL, Jagust WJ, Rabinovici GD: Diverging patterns of amyloid deposition and hypometabolism in clinical variants of probable Alzheimer's disease. Brain 2013;136:844-858.

14 Laforce R Jr, Tosun D, Ghosh P, Lehmann M, Madison CM, Weiner MW, Miller BL, Jagust WJ, Rabinovici GD: Parallel ICA of FDG-PET and PiB-PET in three conditions with underlying Alzheimer's pathology. Neuroimage Clin 2014;4:508-516.

15 Ossenkoppele R, Schonhaut DR, Schöll M, Lockhart SN, Ayakta N, Baker SL, O’Neil JP, Janabi M, Lazaris A, Cantwell A, Vogel J, Santos M, Miller ZA, Bettcher BM, Vossel KA, Kramer JH, Gorno-Tempini ML, Miller BL, Jagust WJ, Rabinovici GD: Tau PET patterns mirror clinical and neuroanatomical variability in Alzheimer's disease. Brain 2016;139:1551-1567.

16 de Souza LC, Corlier F, Habert MO, Uspenskaya O, Maroy R, Lamari F, Chupin M, Lehéricy S, Colliot O, HahnBarma V, Samri D, Dubois B, Bottlaender M, Sarazin M: Similar amyloid- $\beta$ burden in posterior cortical atrophy and Alzheimer's disease. Brain 2011;134:2036-2043.

17 Baumann TP, Duyar H, Sollberger M, Kuhle J, Regeniter A, Gomez-Mancilla B, Schmidtke K, Monsch AU: CSF-tau and CSF-A $\beta_{1-42}$ in posterior cortical atrophy. Dement Geriatr Cogn Disord 2010;29:530-533.

18 Seguin J, Formaglio M, Perret-Liaudet A, Quadrio I, Tholance Y, Rouaud O, Thomas-Anterion C, Croisile B, Mollion H, Moreaud O, Salzmann M, Dorey A, Bataillard M, Coste MH, Vighetto A, Krolak-Salmon P: CSF biomarkers in posterior cortical atrophy. Neurology 2011;76:1782-1788. 
Granadillo et al.: Visual Ratings of Medial Temporal Lobe Atrophy Correlate with CSF

Tau Indices in Clinical Variants of Early-Onset Alzheimer Disease

19 de Souza LC, Lamari F, Belliard S, Jardel C, Houillier C, De Paz R, Dubois B, Sarazin M: Cerebrospinal fluid biomarkers in the differential diagnosis of Alzheimer's disease from other cortical dementias. J Neurol Neurosurg Psychiatry 2011;82:240-246.

20 Formaglio M, Costes N, Seguin J, Tholance Y, Le Bars D, Roullet-Solignac I, Mercier B, Krolak-Salmon P, Vighetto A: In vivo demonstration of amyloid burden in posterior cortical atrophy: a case series with PET and CSF findings. J Neurol 2011;258:1841-1851.

21 Beaufils E, Dufour-Rainfray D, Hommet C, Brault F, Cottier JP, Ribeiro MJ, Mondon K, Guilloteau D: Confirmation of the amyloidogenic process in posterior cortical atrophy: value of the $A \beta_{42} / A \beta_{40}$ ratio. J Alzheimers Dis 2013;33:775-780.

22 Coppi E, Ferrari L, Santangelo R, Caso F, Pinto P, Passerini G, Comi G, Magnani G: Further evidence about the crucial role of CSF biomarkers in diagnosis of posterior cortical atrophy. Neurol Sci 2014;35:785-787.

23 Magnin E, Paquet C, Formaglio M, Croisile B, Chamard L, Miguet-Alfonsi C, Tio G, Dumurgier J, Roullet-Solignac I, Sauvée M, Thomas-Antérion C, Vighetto A, Hugon J, Vandel P: Increased cerebrospinal fluid tau levels in logopenic variant of Alzheimer's disease. J Alzheimers Dis 2014;39:611-616.

24 Teng E, Yamasaki TR, Tran M, Hsiao JJ, Sultzer DL, Mendez MF: Cerebrospinal fluid biomarkers in clinical subtypes of early-onset Alzheimer's disease. Dement Geriatr Cogn Disord 2014;37:307-314.

25 Paterson RW, Toombs J, Slattery CF, Nicholas JM, Andreasson U, Magdalinou NK, Blennow K, Warren JD, Mummery CJ, Rossor MN, Lunn MP, Crutch SJ, Fox NC, Zetterberg H, Schott JM: Dissecting IWG-2 typical and atypical Alzheimer's disease: Insights from cerebrospinal fluid analysis. J Neurol 2015;262:2722-2730.

26 Santangelo R, Coppi E, Ferrari L, Bernasconi MP, Pinto P, Passerini G, Comi G, Magnani G: Cerebrospinal fluid biomarkers can play a pivotal role in the diagnostic work up of primary progressive aphasia. J Alzheimers Dis 2015;43:1429-1440.

27 Ossenkoppele R, Mattsson N, Teunissen CE, Barkhof F, Pijnenburg Y, Scheltens P, van der Flier WM, Rabinovici GD: Cerebrospinal fluid biomarkers and cerebral atrophy in distinct clinical variants of probable Alzheimer's disease. Neurobiol Aging 2015;36:2340-2347.

28 de Leon MJ, DeSanti S, Zinkowski R, Mehta PD, Pratico D, Segal S, Clark C, Kerkman D, DeBernardis J, Li J, Lair L, Reisberg B, Tsui W, Rusinek H: MRI and CSF studies in the early diagnosis of Alzheimer's disease. J Intern Med 2004;256:205-223.

29 Hampel H, Bürger K, Pruessner JC, Zinkowski R, DeBernardis J, Kerkman D, Leinsinger G, Evans AC, Davies P, Möller HJ, Teipel SJ: Correlation of cerebrospinal fluid levels of tau protein phosphorylated at threonine 231 with rates of hippocampal atrophy in Alzheimer disease. Arch Neurol 2005;62:770-773.

30 Herukka SK, Pennanen C, Soininen H, Pirttilä T: CSF A $\beta 42$, tau and phosphorylated tau correlate with medial temporal lobe atrophy. J Alzheimers Dis 2008;14:51-57.

31 Apostolova LG, Hwang KS, Andrawis JP, Green AE, Babakchanian S, Morra JH, Cummings JL, Toga AW, Trojanowski JQ, Shaw LM, Jack CR Jr, Petersen RC, Aisen PS, Jagust WJ, Koeppe RA, Mathis CA, Weiner MW, Thompson PM: 3D PIB and CSF biomarker associations with hippocampal atrophy in ADNI subjects. Neurobiol Aging 2010;31:1284-1303.

32 de Souza LC, Chupin M, Lamari F, Jardel C, Leclercq D, Colliot O, Lehéricy S, Dubois B, Sarazin M: CSF tau markers are correlated with hippocampal volume in Alzheimer's disease. Neurobiol Aging 2012;33:12531257.

33 Carmichael O, Xie J, Fletcher E, Singh B, DeCarli C: Localized hippocampus measures are associated with Alzheimer pathology and cognition independent of total hippocampal volume. Neurobiol Aging 2012;33: 1124.e31-41.

34 Alexopoulos P, Kriett L, Haller B, Klupp E, Gray K, Grimmer T, Laskaris N, Förster S, Perneczky R, Kurz A, Drzezga A, Fellgiebel A, Yakushev I: Limited agreement between biomarkers of neuronal injury at different stages of Alzheimer's disease. Alzheimers Dement 2014;10:684-689.

35 Schönknecht P, Pantel J, Hartmann T, Werle E, Volkmann M, Essig M, Amann M, Zanabili N, Bardenheuer H, Hunt A, Schröder J: Cerebrospinal fluid tau levels in Alzheimer's disease are elevated when compared with vascular dementia but do not correlate with measures of cerebral atrophy. Psychiatry Res 2003;120:231-238.

36 Schoonenboom SN, Visser PJ, Mulder C, Lindeboom J, Van Elk EJ, Van Kamp GJ, Scheltens PH: Biomarker profiles and their relation to clinical variables in mild cognitive impairment. Neurocase 2005;11:8-13.

37 Bouwman FH, Verwey NA, Klein M, Kok A, Blankenstein MA, Sluimer JD, Barkhof F, van der Flier WM, Scheltens P: New research criteria for the diagnosis of Alzheimer's disease applied in a memory clinic population. Dement Geriatr Cogn Disord 2010;30:1-7.

38 Morinaga A, Ono K, Ikeda T, Ikeda Y, Shima K, Noguchi-Shinohara M, Samuraki M, Yanase D, Yoshita M, Iwasa K, Mastunari I, Yamada M: A comparison of the diagnostic sensitivity of MRI, CBF-SPECT, FDG-PET and cerebrospinal fluid biomarkers for detecting Alzheimer's disease in a memory clinic. Dement Geriatr Cogn Disord 2010;30:285-292.

39 Grimmer T, Riemenschneider M, Förstl H, Henriksen G, Klunk WE, Mathis CA, Shiga T, Wester HJ, Kurz A, Drzezga A: Beta amyloid in Alzheimer's disease: increased deposition in brain is reflected in reduced concentration in cerebrospinal fluid. Biol Psychiatry 2009;65:927-934.

40 Scheltens P, Launer LJ, Barkhof F, Weinstein HC, van Gool WA: Visual assessment of medial temporal lobe atrophy on magnetic resonance imaging: interobserver reliability. J Neurol 1995;242:557-560.

41 Koedam EL, Lehmann M, van der Flier WM, Scheltens P, Pijnenburg YA, Fox N, Barkhof F, Wattjes MP: Visual assessment of posterior atrophy development of a MRI rating scale. Eur Radiol 2011;21:2618-2625. 
Granadillo et al.: Visual Ratings of Medial Temporal Lobe Atrophy Correlate with CSF

Tau Indices in Clinical Variants of Early-Onset Alzheimer Disease

42 Dubois B, Feldman HH, Jacova C, Dekosky ST, Barberger-Gateau P, Cummings J, Delacourte A, Galasko D, Gauthier S, Jicha G, Meguro K, O’Brien J, Pasquier F, Robert P, Rossor M, Salloway S, Stern Y, Visser PJ, Scheltens P: Research criteria for the diagnosis of Alzheimer's disease: revising the NINCDS-ADRDA criteria. Lancet Neurol 2007;6:734-746.

43 Gorno-Tempini ML, Hillis AE, Weintraub S, Kertesz A, Mendez M, Cappa SF, Ogar JM, Rohrer JD, Black S, Boeve BF, Manes F, Dronkers NF, Vandenberghe R, Rascovsky K, Patterson K, Miller BL, Knopman DS, Hodges JR, Mesulam MM, Grossman M: Classification of primary progressive aphasia and its variants. Neurology 2011; 76:1006-1014.

44 Mendez MF, Ghajarania M, Perryman KM: Posterior cortical atrophy: clinical characteristics and differences compared to Alzheimer's disease. Dement Geriatr Cogn Disord 2002;14:33-40.

45 Folstein MF, Folstein SE, McHugh PR: "Mini-mental state." A practical method for grading the cognitive state of patients for the clinician. J Psychiatr Res 1975;12:189-198.

46 Cicchetti DV: Guidelines, criteria, and rules of thumb for evaluating normed and standardized assessment instruments in psychology. Psychol Assess 1994;6:284-290.

47 Harper L, Fumagalli GG, Barkhof F, Scheltens P, O’Brien JT, Bouwman F, Burton EJ, Rohrer JD, Fox NC, Ridgway GR, Schott JM: MRI visual rating scales in the diagnosis of dementia: evaluation in 184 post-mortem confirmed cases. Brain 2016;139:1211-1225.

48 Blomberg M, Jensen M, Basun H, Lannfelt L, Wahlund LO: Cerebrospinal fluid tau levels increase with age in healthy individuals. Dement Geriatr Cogn Disord 2001;12:127-132.

49 Ganzer S, Arlt S, Schoder V, Buhmann C, Mandelkow EM, Finckh U, Beisiegel U, Naber D, Müller-Thomsen T: CSF-tau, CSF-A $1-42$, ApoE-genotype and clinical parameters in the diagnosis of Alzheimer's disease: combination of CSF-tau and MMSE yields highest sensitivity and specificity. J Neural Transm 2003;110:1149-1160.

50 Wagshal D, Sankaranarayanan S, Guss V, Hall T, Berisha F, Lobach I, Karydas A, Voltarelli L, Scherling C, Heuer H, Tartaglia MC, Miller Z, Coppola G, Ahlijanian M, Soares H, Kramer JH, Rabinovici GD, Rosen HJ, Miller BL, Meredith J, Boxer AL: Divergent CSF tau alterations in two common tauopathies: Alzheimer's disease and progressive supranuclear palsy. J Neurol Neurosurg Psychiatry 2015;86:244-250.

51 Seppälä TT, Koivisto AM, Hartikainen P, Helisalmi S, Soininen H, Herukka SK: Longitudinal changes of CSF biomarkers in Alzheimer's disease. J Alzheimers Dis 2011;25:583-594.

52 Ossenkoppele R, Cohn-Sheehy BI, La Joie R, Vogel JW, Möller C, Lehmann M, van Berckel BN, Seeley WW, Pijnenburg YA, Gorno-Tempini ML, Kramer JH, Barkhof F, Rosen HJ, van der Flier WM, Jagust WJ, Miller BL, Scheltens P, Rabinovici GD: Atrophy patterns in early clinical stages across distinct phenotypes of Alzheimer's disease. Hum Brain Mapp 2015;36:4421-4437.

53 Shiino A, Watanabe T, Kitagawa T, Kotani E, Takahashi J, Morikawa S, Akiguchi I: Different atrophic patterns in early- and late-onset Alzheimer's disease and evaluation of clinical utility of a method of regional z-score analysis using voxel-based morphometry. Dement Geriatr Cogn Disord 2008;26:175-186.

54 Gordon BA, Friedrichsen K, Brier M, Blazey T, Su Y, Christensen J, Aldea P, McConathy J, Holtzman DM, Cairns NJ, Morris JC, Fagan AM, Ances BM, Benzinger TL: The relationship between cerebrospinal fluid markers of Alzheimer pathology and positron emission tomography tau imaging. Brain 2016;139:2249-2260.

55 Tuokkola T, Koikkalainen J, Parkkola R, Karrasch M, Lötjönen J, Rinne JO: Visual rating method and tensorbased morphometry in the diagnosis of mild cognitive impairment and Alzheimer's disease: a comparative magnetic resonance imaging study. Acta Radiol 2016;57:348-355.

56 Vermersch P, Leys D, Scheltens P, Barkhof F: Visual rating of hippocampal atrophy: correlation with volumetry. J Neurol Neurosurg Psychiatry 1994;57:1015.

57 Bresciani L, Rossi R, Testa C, Geroldi C, Galluzzi S, Laakso MP, Beltramello A, Soininen H, Frisoni GB: Visual assessment of medial temporal atrophy on MR films in Alzheimer's disease: comparison with volumetry. Aging Clin Exp Res 2005; 17:8-13.

58 Victoroff J, Ross GW, Benson DF, Verity MA, Vinters HV: Posterior cortical atrophy. Neuropathologic correlations. Arch Neurol 1994;51:269-274.

59 Renner JA, Burns JM, Hou CE, McKeel DW Jr, Storandt M, Morris JC: Progressive posterior cortical dysfunction: a clinicopathologic series. Neurology 2004;63:1175-1180. 